PostgRaD. MED. J. (1965), 41, 481

\title{
PRE- AND POST-OPERATIVE CARE OF PATIENTS WITH PHAEOCHROMOCYTOMAS
}

\author{
A. I. G. Robertson, F.F.A., R.C.S., D.A. \\ University College Hospital, London, W.C.1.
}

IN DEALING with phæochromocytomas the anæsthetist must be ready to combat hypertensive crises, severe tachycardia, perhaps heavy blood loss and subsequently hypotension, which may be extreme.

The patient with a phæochromocytoma may present with a persistent hypertension without crises, a persistent hypertension with crises, or a normotension with crises. Glycosuria may be present but is of no importance to the anæsthetist as it will disappear on removal of the tumour. The patient may be pregnant and pregnancy appears to precipitate the malady or at least lead to its discovery. The anæsthetic management of each of these variations of the disease is similar.

The tumour itself may be in either adrenal gland adjacent to an adrenal, in the para-aortic area, around the renal artery, in the chest or in the bladder. There may be multiple tumours and they may be malignant. These tumours tend to be very vascular and those in the paraaortic area dangerously tied down to large blood vessels; as the circulating blood mass in these patients is reduced, presumably because of persistent vasoconstriction, blood loss is dangerous and must be replaced, particularly in view of the fall in blood pressure anticipated when the tumour is excised.

The catecholamines secreted by a phæochromocytoma are adrenaline and noradrenaline; rarely a tumour may secrete only one of these amines. The cardiovascular, metabolic, endocrine and mental manifestations of these amines are well known and will not be repeated here. It may however be mentioned that these patients tend to be more nervous than the average and require more sedation for their peace of mind.

There are five periods of particular danger in the surgery of phæochromocytomas: induction, (with thiopentone), intubation, the positioning of the patient on the operating table, when a technician may press on the tumour or supports may pass into it, the surgical manipulation of the tumour (when what is tantamount to an intravenous injection of amines occurs), and the final ligation of the venous drainage. If the blood pressure does not fall on the excision of the tumour it indicates the presence of another phæochromocytoma and this must be looked for; the removal of another tumour and a fall in blood pressure indicates the success of the operation.

The effects of the catecholamines are mediated through $\alpha$ and $\beta$ receptors; the $\alpha$ receptors are associated with excitatory responses such as hypertension and the $\beta$ receptors with inhibitory responses. There is an exception to this rule in that $\beta$ receptor stimulation gives rise to an increase of rate and force of the heart beat. It may be noted further that adrenaline stimulates both receptors while noradrenaline mainly effects the $\alpha$ receptors.

There are available today drugs which will block both receptors. Phenoxybenzamine and phentolamine block the $\alpha$ receptors and pronethalol and propranolol the $\beta$ receptors. The preparation of a patient for surgery consists in the use of these drugs.

Phenoxybenzamine is a potent and longacting (over 24 hours) drug blocking the excitatory responses of smooth muscle to adrenergic stimuli. Phentolamine is a potent but short-acting (a period of a few minutes) drug with the same actions. Both unfortunately have the effect of producing a tachycardia, more marked with phentolamine.

Pronethalol and propranolol reduce or block many of the effects of catecholamines on the heart such as increase of force and rate of heart beat and the appearance of extrasystoles. These drugs must not be used if the patient is in heart failure as they appear to block the sympathetic drive and aggravate the cardiovascular situation.

The anæsthetist may be presented with a phæochromocytoma under three different circumstances:-

(1) The tumour which has been diagnosed and localised. 


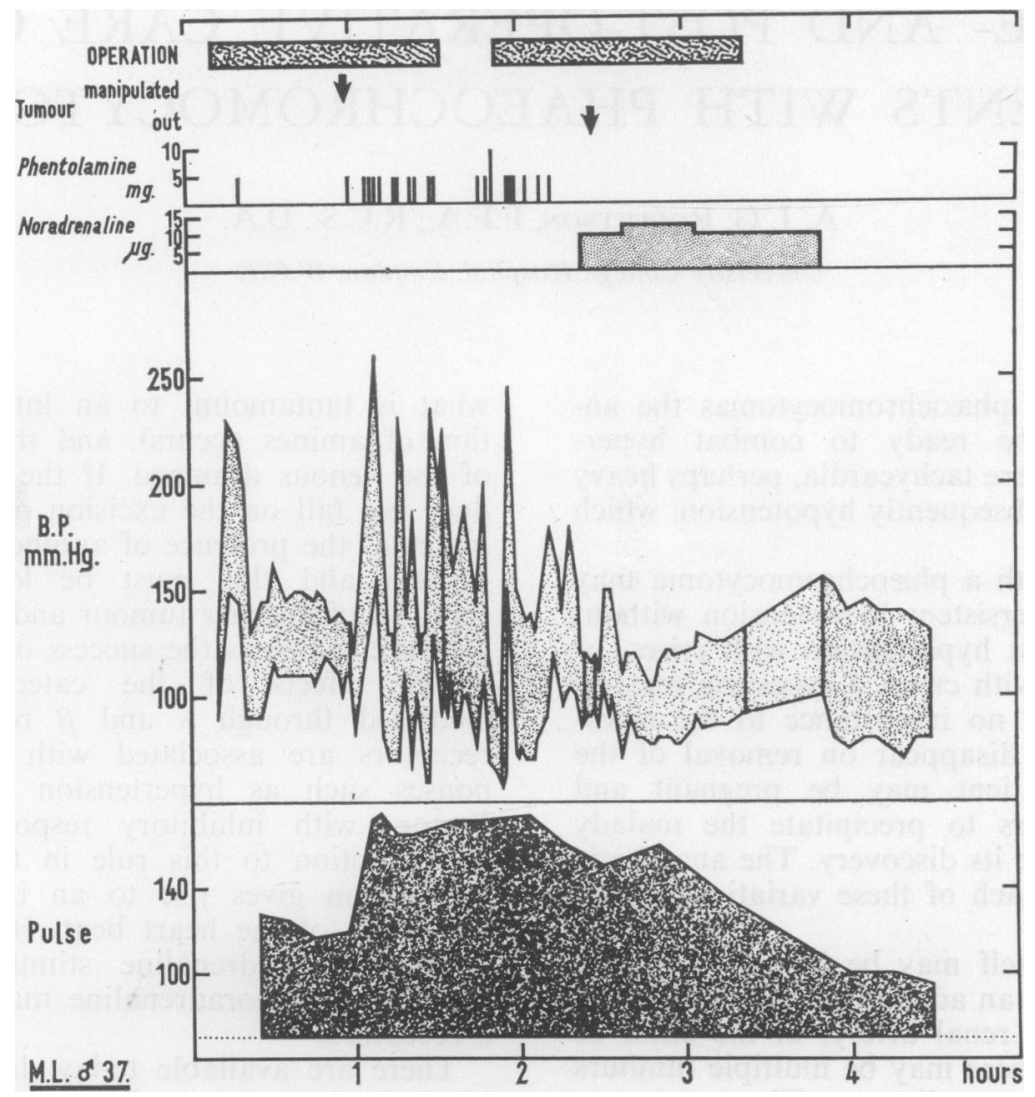

FIG. 1.-Shows a case controlled by phentolamine alone and the marked tachycardia that can occur. It shows also the rise in blood pressure on induction and the satisfactory response to noradrenaline.

(2) The tumour which has been diagnosed but not localised.

(3) During an operation for some other condition, especially during an aortogram in the differential diagnosis of hypertension, a hypertensive crisis may occur with tachycardia.

Number 3 is an emergency and should be treated with phentolamine $(5 \mathrm{mg}$.) intravenously which will reduce the hypertension and, if available, propranolol 10 to $20 \mathrm{mg}$. slowly over some three to five minutes intravenously, which will reduce the tachycardia. If the operation is an abdominal one a search may be made for the tumour and if found it could be excised if noradrenaline is available; but it is probably wiser to finish whatever procedure is being undertaken and make a formal approach to the phæochromocytoma.

When it is considered how many hyperten- sive patients are operated on and that according to Smithwick $0.5 \%$ of cases of hypertension are due to a phæochromocytoma it is remarkable how rare this emergency is, although the writer knows of two, one of which ended fatally. Furthermore, in seven out of twenty cases of phæochromocytoma on which this paper is based a profound rise in blood pressure with tachycardia occurred on induction with thiopentone. It would appear that as routine blood pressures are not generally taken in anæsthesia some crises must pass unnoticed and the patient comes to no harm. Several of the twenty cases mentioned had had previous operations and anæsthetics without ill-effects although of course it is not known if they had a functioning phæochromocytoma at that time.

When the tumour has been localised, preoperative preparation with phenoxybenzamine 


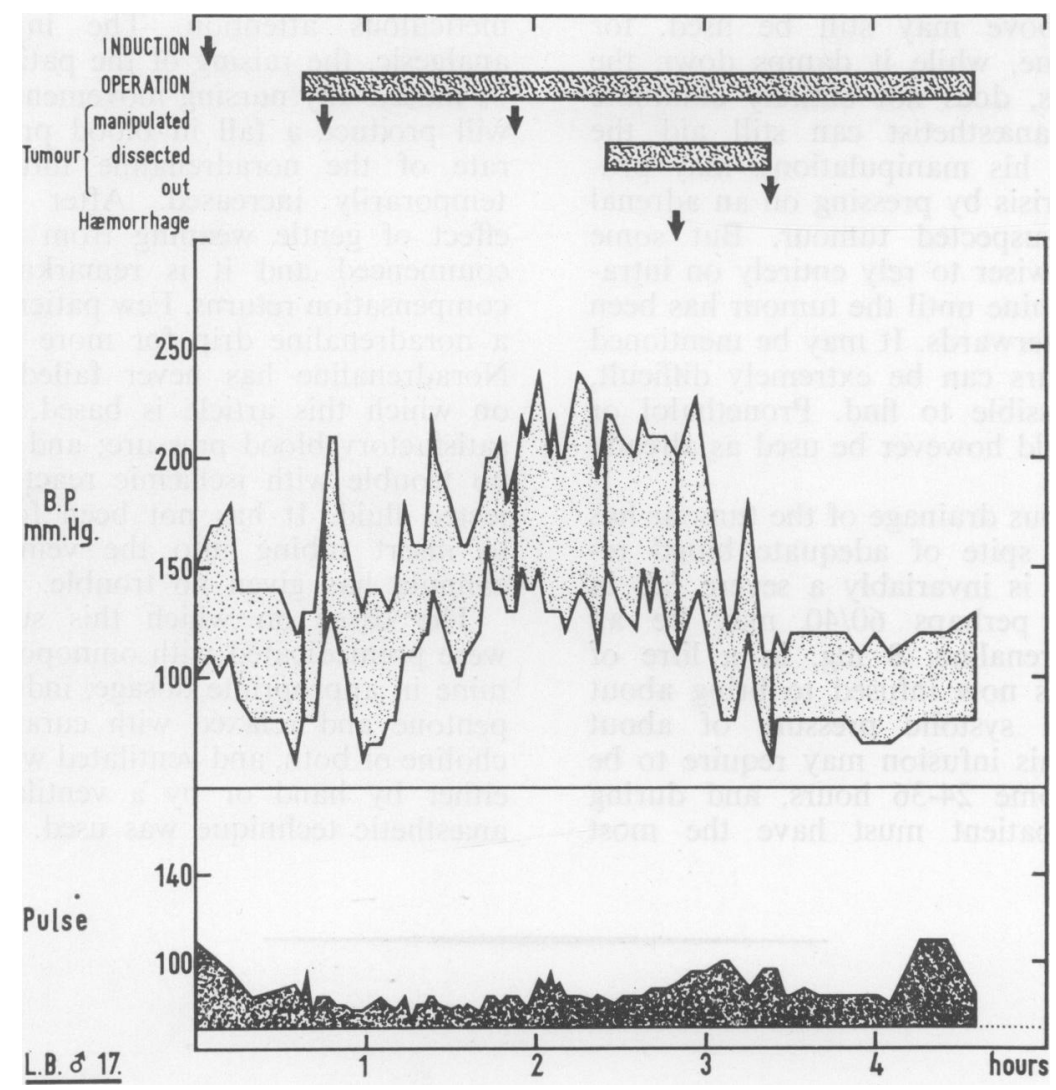

Fig. 2.-Shows a case controlled with phenoxybenzamine and pronethalol; it demonstrates the stability of the pulse rate.

and pronethalol or propranolol should be undertaken. It is probably best to administer phenoxybenzamine as an intravenous infusion slowly, over an hour, in a dosage of $1 \mathrm{mg}$. per kilo body weight (diluted to $500 \mathrm{ml}$.) on the three preoperative evenings. This will reduce the blood pressure to a more physiological level and because of its long duration of action give some cover against pressor reactions; if during the manipulation of the tumour severe crises occur, say in a young or middle aged patient, a blood pressure of over $280 / 160 \mathrm{~mm}$. $\mathrm{Hg}$. phentolamine intravenously in a dosage of $5 \mathrm{mg}$. repeated as required will give a rapid reduction of blood pressure. The anæsthetist must use his judgement regarding the physical condition of the patient as to how high to allow the blood pressure to rise without treatment. The patient treated with phenoxybenzamine comes to the operating theatre in markedly superior condition to those not so premedicated; he is drowsy (not apprehensive) vasodilated and the blood pressure is reduced. During the operation less phentolamine, if any, is required. There appears to be no danger of subseqeuently blocking the action of noradrenaline.

While phenoxybenzamine will control the pressor response to the catecholamines it has no effect on the tachycardia and indeed as has been mentioned, has a moderate pressor response on the pulse rate. Pronethalol or propranolol will eliminate any rise in pulse rate. Pronethalol should be given in a dosage of $100 \mathrm{mg}$. t.d.s. for the three pre-operative days and including the morning of operation as its duration of action is short. Alternatively propranolol may be given in a dosage of $20 \mathrm{mg}$. t.d.s. over a similar period. Up to the present propranolol has not appeared to be as effective as pronethalol, perhaps the dosage has been too small; in any case the tumour-producing effect of pronethalol can be ignored when the period of administration is so brief.

When the tumour has not been localised the 
regime given above may still be used, for phenoxybenzamine, while it damps down the pressor responses, does not entirely eliminate them and the anæsthetist can still aid the surgeon who, in his manipulations, may produce a sudden crisis by pressing on an adrenal gland or any suspected tumour. But some may consider it wiser to rely entirely on intravenous phentolamine until the tumour has been identified and afterwards. It may be mentioned that these tumours can be extremely difficult, sometimes impossible to find. Pronethalol or propranolol should however be used as already described.

When the venous drainage of the tumour has been ligated, in spite of adequate blood replacement, there is invariably a severe fall in blood pressure, perhaps 60/40 may be an average. Noradrenaline, $8 \mathrm{mg}$. in a litre of dextrose saline is now infused to bring about and maintain a systolic pressure of about $120 \mathrm{~mm}$. Hg. This infusion may require to be continued for some 24-36 hours, and during this time the patient must have the most meticulous attention. The injection of an 3 analgesic, the raising of the patient in the bed, $\stackrel{\mathbb{Q}}{\mathrm{C}}$ or indeed any nursing movement of the patient $c$. will produce a fall in blood pressure and the $\overrightarrow{\vec{F}}$ rate of the noradrenaline infusion must be $\frac{?}{\circ}$ temporarily increased. After 24 hours the $\frac{-}{5}$ effect of gentle weaning from the infusion is $\overline{\frac{}{5}}$. commenced and it is remarkable how soon $\overrightarrow{\widetilde{\sigma}}$ compensation returns. Few patients have needed $\cong$ a noradrenaline drip for more than 24 hours. $\%$ Noradrenaline has never failed, in the cases $\vec{O}$ on which this article is based, to maintain a satisfactory blood pressure; and there has been $\omega_{\sigma}$ no trouble with ischæmic reactions to the in $-\frac{5}{\circ}$ jected fluid. It has not been found necessaryo to insert tubing into the vein; an ordinary cannula has given no trouble.

The cases on which this survey is based were premedicated with omnopon and scopolamine in appropriate dosage, induced with thio- $\stackrel{+}{\rightarrow}$ pentone and relaxed with curare or succinylcholine or both, and ventilated with $\mathrm{N}_{2} \mathrm{O}$ and $\mathrm{O}_{2} \stackrel{5}{工}$ either by hand or by a ventilator. No other anæsthetic technique was used. 